\title{
Trend of caesarean section at two Government Medical College in Madhya Pradesh, India over one year of time period: a retrospective comparative study
}

\author{
Poonam Mathur, Alka Patel*
}

Department of Obstetrics and Gynecology, MGM Medical College, Indore, Madhya Pradesh, India

Received: 17 April 2018

Accepted: 20 April 2018

*Correspondence:

Dr. Alka Patel,

E-mail: alkapatelmgmc@gmail.com

Copyright: () the author(s), publisher and licensee Medip Academy. This is an open-access article distributed under the terms of the Creative Commons Attribution Non-Commercial License, which permits unrestricted non-commercial use, distribution, and reproduction in any medium, provided the original work is properly cited.

\begin{abstract}
Background: There is a massive public interest and debate on both the cause and appropriateness of increasingly employing a surgical procedure to short circuit or entirely bypass labour and delivery. The indications of caesarean sections vary among institutions as there is no standard classification system exists for indications of C-Section. Present study analysed pattern of caesarean section at two tertiary centre in Madhya Pradesh, India.

Methods: A structured proforma was filled up for every case and results were recorded on excel sheet. All the cases included in study were further divided in group 1 (deliveries conducted in year 2014-2015 at Govt. Medical College Indore, M.P.), group 2 (deliveries conducted at Govt. Medical College Rewa at same time. Comparative analysis between study group1 and group 2 was done using Pearson Chi square test.

Results: In group 1 there were 10525 deliveries out of which 3705 were delivered by caesarean section (35.2\%), in group 2 there were 8674 deliveries out of which 1182 were delivered by caesarean section (13.6\%). This difference in caesarean section at both medical college may be due to the more no. of referrals from the periphery to the medical college Indore and having more no of private institutions and district hospital which cater the normal delivery.

Conclusions: There is a reliable and reproducible framework is required for audit and analysis of Caesarean section trends in specific obstetric subgroups to permit comparisons of practice between different institutions and over time in the same institution.
\end{abstract}

Keywords: Caesarean section, Caesarean section rate, Retrospective comparative study

\section{INTRODUCTION}

High caesarean section rate has been recognized as a major health problem in many countries. There is a massive public interest and debate on both the cause and appropriateness of increasingly employing a surgical procedure to short circuit or entirely bypass labour and delivery. ${ }^{1}$ Although, caesarean delivery greatly improves obstetric outcomes when clinically indicated, excessively high caesarean delivery rates have raised concern about the health and economic consequences of this practice. ${ }^{2}$
CS rates vary worldwide with rates ranging from $21.5 \% 1$ in Britain to $29.1 \% 2$ in USA with some Latin American countries going as high as $40 \% .^{3}$ Similar trends have also been documented in India, according to ICMR study conducted in 30 teaching hospitals in India; there is an increase in CS rates from $21.8 \%$ in $1993-1994$ to $25.4 \%$ in $1998-1999 .{ }^{4}$ according to WHO, though there is no ideal CS rate, CS rates above $10-15 \%$ does not confer additional health benefits in terms of foetal and maternal morbidity and mortality. ${ }^{5}$ The increasing trend of CS rates may indicate a trend towards a more costly medical 
delivery systems and lowered threshold of abnormality detection among the health care providers. ${ }^{6}$ In India During last decade Janani Suraksha Program and maternal ambulances services have brought many significant changes in maternal and perinatal outcomes in India, one of which is significantly increased number of institutional deliveries, this may have brought a difference in pattern of caesarean sections as well, analysis of which has not been incorporated in much of the studies.

The indications of caesarean sections vary among institutions as there is no standard classification system exists for indications of $\mathrm{C}$-Section. ${ }^{7,8} \mathrm{~A}$ major challenge is that definitions are not standardized and indications can be multiple or related. ${ }^{9}$ In order to understand the degree to which caesarean deliveries may be preventable, it is important to know why caesareans are performed. This study is aimed to find the rate of caesarean deliveries, various indications of the procedure and their relative contribution to the total Caesarean section rate (CSR) at two different medical college in M.P. at same time.

\section{METHODS}

This study was a hospital-based retrospective study, conducted in a tertiary government health care set up specializing in Obstetrics and Gynaecology in Gov. Indore Medical College, Madhya Pradesh, India. All the patients who underwent Caesarean Section in the year of 2014-2015 were included in the study. Data on all live births were collected. In cases of caesarean sections their indications were recorded along with other demographic profile like age, residence-urban/rural. Whether procedure was done as an emergency or it was a planned surgery. Previous obstetrics history and present obstetric parameters like antenatal care, gestational age, lie and presentation, no. of foetuses etc. were also recorded in the format and later entered in the Microsoft excel sheet and Data were compared with caesarean deliveries conduct in Rewa Medical college in the year of 2014-2015

So, All the cases included in study were further divided in group 1 and group 2 as following:

- Group 1: all the caesarean deliveries done in year 2014-2015 in Govt. Indore Medical College, M.P.
- Group 2: All the caesarean deliveries done in year 2014-2015 in Govt. Rewa Medical College, M.P.

\section{Inclusion criteria}

All the cases of caesarean delivery during study time were included.

\section{Exclusion criteria}

Clinically diagnosed cases of ruptured uterus and proven on laparotomy.

\section{Statistical analysis}

Comparative analysis between study group 1 and group 2 was done using Pearson Chi square test. Differences with $\mathrm{p}$ values of less or equal to 0.05 was considered statistically significant.

\section{RESULTS}

As shown in table 1, in group 1, total number of deliveries during the study period was 10525 , out of which 3705 (35.20\%) was caesarean deliveries. In group 2 total number of deliveries during study period was 8674 , out of which $1182(13.62 \%)$ were caesarean deliveries. There is significant no. of total number of deliveries $(\mathrm{p}<0.001)$ a caesarean section rate $(\mathrm{p}<0.001)$ in group 1 as compare to group 2 .

Table 1: Incidence of total deliveries and caesarean section.

\begin{tabular}{|llll|} 
Group & $\begin{array}{l}\text { Total } \\
\text { deliveries }\end{array}$ & $\begin{array}{l}\text { Total } \\
\text { caesarean }\end{array}$ & Percentage \\
\hline 1 & 10525 & 3705 & $35.20 \%$ \\
\hline 2 & 8674 & 1182 & $13.62 \%$ \\
\hline
\end{tabular}

As evident from Table 2, in group 1, out of 3705; 35 $(0.95 \%)$ cases were less than 18 year of age, while in group 2 out of $1182 ; 2(0.16 \%)$ cases were less than 18 year of age. There is no significant change in distribution of cases in age group of 18-35 year and > 35 year.

Table 2: Distribution of cases according to age.

\begin{tabular}{|c|c|c|c|c|c|c|c|}
\hline \multirow{2}{*}{ Group } & \multicolumn{2}{|c|}{$<18$ yrs } & \multicolumn{2}{|c|}{ 18-35 yrs } & \multicolumn{2}{|c|}{$>35$ yrs } & \multirow{2}{*}{ Total } \\
\hline & No. & $\%$ & No. & $\%$ & No. & $\%$ & \\
\hline 1 & 35 & 0.95 & 3570 & 96.35 & 100 & 2.69 & 3705 \\
\hline 2 & 02 & 0.16 & 1168 & 98.8 & 12 & 1.01 & 1182 \\
\hline
\end{tabular}

Table 3 compares parity between two groups, in group1, among 3705 patients, 1265 (34.14\%) were nulliparous while 2440 (64\%) were multiparous. In group2, among 1182 patients $596(50.40 \%)$ were nulliparous while 586 
(49.5\%) were multiparous. There is significant change in parity between group 1 and group 2 .

Table 3: Distribution of cases according to parity.

\begin{tabular}{|l|lllll|}
\hline \multirow{2}{*}{ Group } & \multicolumn{2}{l}{ Nullipara } & \multicolumn{2}{l|}{ Multipara } & Total \\
\hline 1 & No & \% & No & \% & \\
\hline 2 & 1789 & 48.28 & 1916 & 51.71 & 3705 \\
\hline
\end{tabular}

Table 4: Distribution of cases according to residence.

\begin{tabular}{|l|lllll|}
\hline Group & Rural & \multicolumn{3}{c}{ Urban } & Total \\
& No & \% & No & $\%$ & \\
\hline 1 & 1286 & 34.71 & 2419 & 65.28 & 3705 \\
\hline 2 & 933 & 78.9 & 249 & 21.06 & 1182 \\
\hline
\end{tabular}

It is evident from Table 4 that in group 1, among 3705 patients, $1286(34.71 \%)$ belonged to rural area while $2419(65.28 \%)$ were from urban area. In group2, among 1182 patients, 933 (78.9\%) belonged to rural population while only $249(21.06 \%)$ were from urban population. There is significant change in distribution $(\mathrm{p}<0.001)$ between the group1 and group2, regarding females coming from rural area.

Table 5: Distribution of cases according to booking status.

\begin{tabular}{|l|lllll|}
\hline \multirow{2}{*}{ Group } & \multicolumn{2}{l}{ Booked } & \multicolumn{2}{l|}{ Unbooked } & Total \\
\hline 1 & No & \% & No & \% & \\
\hline 2 & 1559 & 42.07 & 2146 & 57.92 & 3705 \\
\hline & 516 & 43.65 & 666 & 56.2 & 1182 \\
\hline
\end{tabular}

As evident from Table 5 In group1, out of 3705 patients $1659(42.07 \%)$ were booked, 2046(57.92\%) were unbooked. In group 2, among 1182 patients $516(43.65 \%)$ were booked, $302(25.5 \%)$ were partially booked, 364 $(30.7 \%)$ were unbooked. There is significant difference in booking status between group1 and group 2But in both the group no of unbooked patients are more.

Table 6: Distribution of cases according to type of caesarean.

\begin{tabular}{|c|c|c|c|c|c|}
\hline \multirow{2}{*}{ Group } & \multicolumn{2}{|c|}{ Primary } & \multicolumn{2}{|c|}{ Repeat } & \multirow[b]{2}{*}{ Total } \\
\hline & No & $\%$ & No & $\%$ & \\
\hline 1 & 2528 & 68.23 & 1177 & 31.76 & 3705 \\
\hline 2 & 802 & 69.85 & 380 & 32.15 & 1182 \\
\hline
\end{tabular}

Above Table 6 suggests that in group1, primary caesarean sections done were $2528(68.23 \%)$ cases and repeat caesarean sections were $1177(31.76 \%)$ cases. In group2 out of 1182 cases, $802(69.85 \%)$ were primary caesarean and $380(32.15 \%)$ were repeat caesarean section. There is no significant difference in rate of repeat caesarean sections in both the groups.
Table 7: Distribution of cases according to indication of operation.

\begin{tabular}{|lllll|}
\hline \multirow{2}{*}{ Indication of operation } & \multicolumn{2}{l}{ Group1 } & \multicolumn{2}{l}{ Group2 } \\
& No & \% & No & $\%$ \\
\hline Fetal distress+MSL & 691 & 18.65 & 329 & 27.85 \\
\hline Previous section & 1177 & 31.76 & 380 & 32.15 \\
\hline CPD & 328 & 8.85 & 163 & 13.79 \\
\hline PROM & 114 & 3.08 & 54 & 4.57 \\
\hline PIH+Preeclampsia & 114 & 3.08 & 99 & 8.38 \\
\hline Breech & 240 & 6.47 & 98 & 8.29 \\
\hline Placenta & 116 & 3.13 & 44 & 3.72 \\
previa+abruptio & & & & \\
\hline POP+DTA & 48 & 1.29 & 11 & 0.93 \\
\hline Obstructed labour & 52 & 1.40 & 42 & 3.55 \\
\hline Failed induction & 310 & 8.36 & 126 & 10.65 \\
\hline Transverse lie & 66 & 1.78 & 81 & 6.85 \\
\hline Face + brow & 13 & 0.35 & 7 & 0.59 \\
\hline Cord prolapse & 29 & 0.78 & 12 & 1.015 \\
\hline Multiple pregnancy & 30 & 0.81 & 25 & 2.19 \\
\hline Compound presentation & 55 & 1.48 & 3 & 0.25 \\
\hline Eclampsia & 52 & 1.40 & 8 & 0.68 \\
\hline NPOL & 258 & 6.97 & 70 & 5.92 \\
\hline Oligohydramnios+IUGR & 159 & 4.29 & 72 & 6.1 \\
\hline
\end{tabular}

As it is evident from Table 7 that in both the groups previous section was the most common indication followed by fetal distress, CPD and failed induction. In group 1 further most common indications were non progress of labour, breech, oligohydramnios and IUGR. While in group2 pre-eclampsia, breech, transverse lie, oligohydramnios and IUGR and non progress of labour.

\section{DISCUSSION}

The present study is a retrospective hospital record based study, carried out at the department of obstetrics and gynaecology at Mahatma Gandhi Memorial Medical College and associated Maharaja Yashwant Rao Hospital, Indore M.P. to assess pattern of caesarean section and further this study was compared with pattern of caesarean section in Shyam Shah Medical College and associated Gandhi Memorial Hospital Rewa.

\section{Socio demographic characteristics of study population}

Age

Maximum number of caesarean sections in group1 and group 2 were in age group of 18 to 35 years of age which was $96 \%$ and $98 \%$ respectively, which is comparable with the Naidu $\mathrm{P}$ et al study done in South coastal India. ${ }^{10-14}$ It also reflects the maximum fertile period of women"s life and common child bearing age group.

Parity

The maximum numbers of caesarean cases were observed in primiparous women in group $2(50.4 \%) \mathrm{r}$ which are 
comparable to study done by Kumar A at Shimla, and Soin et al. ${ }^{12,13}$

While in group1 maximun no of cases observed in multiparous women $(51.7 \%)$. In a study by Unnikrishnan B et al, $47.8 \%$ cases were primiparous and $46.6 \%$ were multiparous which is comparable to present study group2

\section{Residence}

In group1 urban population is main contributor $(65 \%)$ while In the group2 rural population is main contributor (79\%), this may due to Rewa Medical College is at periphery and covers more of Rural population.

\section{Booking status}

Maximum number of cases in both group belonged to partially unbooked status (57.9\%, 56.2\% respectively) which is comparable with study done by Subedi S where $98 \%$ cases were unbooked or partially booked. ${ }^{15}$ In a study done by Haider $\mathrm{G}$ et al done in Hyderabad Sindh, $56 \%$ cases were unbooked, Hafeeze $M$ et al reported $61.38 \%$ unbooked cases while in study done by Unnikrishnan B et al, $87.5 \%$ case were booked which could be reflection of overall better health indicators in South Indian States in our country. ${ }^{14,16,17}$

\section{Type and incidence of caesarean section}

In present study majority of the caesarean sections in group $1(68.5 \%)$ were emergency compared with only $31.5 \%$ of elective Caesarean delivery, in group $2(71.6 \%)$ were emergency and $28.4 \%$ were elective, Mutihir et al reported similar findings. ${ }^{18}$ This high rate of emergency Caesarean section could be attributed to the fact that these are tertiary health facilities which serve as referral centers where complicated labors could be managed more effectively. In most cases, the lifesaving CS remains the only choice. ${ }^{19}$ Another possibility is the dearth of expertise at secondary health facilities in these regions. Therefore, experts that could manage complicated labour are only available at the tertiary health facilities.

During the study period in group 1 there were 10525 deliveries out of which 3705 were delivered by caesarean section $(35.2 \%)$, in group 2 there were 8674 deliveries out of which 1182 were delivered by caesarean section $(13.6 \%)$. There is significant more in incidence of caesarean section in group 1 as compared to group 1 . This rise in caesarean section rate is comparable with B Unnikrishnan et al (23.27\%), Shanti Set al (19.9\%), Sobande A et al $(21.1 \%)$, while Gulfareen $\mathrm{H}$ et al found $64.7 \%$ caesarean rate in their study done in Hyderabad, Sindh Pakistan in a tertiary care hospital. ${ }^{14,15,19,20}$

This difference in caesarean section at both medical college may be due to the more no of referrals from the periphery to the Medical College Indore And having more no of private institutions and district hospital which cater the normal delivery as compare to Rewa medical college. most of the population in Rewa comes to medical college for delivery as district hospital there is not well functioning and very few private hospital.

\section{Indication of caesarean section}

The most common indication for which caesarean section performed in our study was repeat caesarean section, in group 1was $31.76 \%$ and in group 2 it was $32.2 \%$. Lubna Ali from Karachi Pakistan reported repeat caesarean section the commonest indication for caesarean section. Similar trends have been found in Northern Greece $(30.9 \%)$ by Mersaovdi et al. ${ }^{21,22}$ B Unnikrishnan et al. ${ }^{14}$ So the decision for primary caesarean section is important unless there is a clear, compelling and well supported justification for caesarean section, a carefully supervised justified trial of labour is necessary. ${ }^{23,24}$ This can be further minimized by routine practice of a trial of labour of Vaginal Birth After Caesarean (VBAC). In the UK, the rate of VBAC is high at $33 \% .{ }^{14}$ Trial of scar in singleton pregnancies can be given to reduce the rate of repeated caesarean section as the risk of uterine rupture is low $0.3 \% .^{26}$

Successful vaginal birth after caesarean (VBAC) in grand multiparous does not lead to increased maternal complication. ${ }^{27}$ One study by McMahon et al noted that higher rates of maternal and foetal morbidity exist with VBAC as compared to elective caesarean. ${ }^{28}$ However, the study by Gonen found that VBAC with a well defined protocol was found to safe for the mother and infant as a planned caesarean delivery and can be encouraged. ${ }^{29}$ Doctors, in general, should be encouraged to take time to provide adequate counselling to the patients about the short comings and advantages of VBAC and help them make informed decisions about opting for CS or vaginal delivery.

In present study, second most common indication for performing caesarean section in both group was foetal distress accounted for $18.65 \%$ in group 1 and $27.85 \%$ in group2. this is comparable to B Unnikrishnan et al ${ }^{14}$ and $\mathrm{R}$ Subhashini et al. ${ }^{30}$ The accurate method for establishment of foetal distress is to perform foetal scalp blood $\mathrm{pH}$ estimation which is considered the gold standard for the assessment of foetal well-being; but is not performed in our setup. Cardiotocographic (CTG) monitoring is known to overestimate the foetal distress. ${ }^{31}$ Many gestational and antepartum factors and uteroplacental vascular disease, fetal sepsis, reduced fetal reserves, reduced uterine perfusion and cord compression can be involved singularly or in combination to influence the fetal response in a CTG. ${ }^{32}$ Methods of screening and diagnosing the condition thus have limitations. ${ }^{33}$

Third most common indication for which caesarean section performed in our study was Cephalopelvic disproportion (CPD) in both group1 and group 2 (8.85\% and $13.79 \%$ respectively). This is comparable to Gupta M 
et al. $^{35}$ Further for the repeat Cesarean, there is an increase in the number of cases with CPD. ${ }^{34}$

The fourth most common indication for which caesarean section done in both group was Failed medical induction, $8.36 \%$ and $10.65 \%$ in group1 and group2 respectively. this is comparable to study done by Arulkumaran et al $(16.5 \%)$ Unnikrishnan B et al $(8.8 \%) .{ }^{12,14}$ Dunne $\mathrm{C}$ et al found that elective induction leads to more unplanned caesarean section in nulliparous women and to increased postpartum complication for both nulliparous and multiparous women. ${ }^{36}$

Other important indications for which caesarean performed in both groups were Non progress of labour $(6.9 \%, 5.9 \%)$, Breech presentation $(6.5 \%$, 8.3\%), oligohydramnios and IUGR $(4.3 \%, 6.1 \%)$ and preeclampsia $(3.1 \%, 8.38 \%)$, this is comparable to Jawa A et al, Gupta $\mathrm{M}$ et al. ${ }^{34,37}$

Judicious use of oxytocics in cases of failure to progress will help reduce the rate of CS resulting from cases of failure of vaginal delivery to progress. Maintenance of a partogram is also found to be beneficial. ${ }^{38}$ Breech presentation accounted for a significant percentage of the non absolute indications for CS. External Cephalic Version (ECV) has been suggested as an intervention to reduce high $\mathrm{CS}$ rates at 37 weeks' gestation. However, ECV has its drawbacks; it requires skill and might not be successful.

During the last two decades there have been an increased number of caesarean sections carried out 'on demand' i.e. at the patient's request and not on any justifiable obstetric reason. Though, such an indication was not documented in our study but low threshold of caesarean section in certain cases cannot be ruled out.

\section{CONCLUSION}

Greatest emphasis attached to foetal welfare in today's small family norm has changed the delivery practices in favour of C-Section. There is no empirical evidence for an optimum percentage. What matters most is that all women who need caesarean sections receive them (WHO Statement 2010). There is need to develop protocols that could potentially reduce the caesarean rates. If this is to happen, however, a reliable and reproducible framework is required for audit and analysis of CS trends in specific obstetric subgroups to permit comparisons of practice between different institutions and over time in the same institution. If Ten Group Classification System(TGCS) used in our country, we can compare our own rates with National and international caesarean rates, this will also help in not only identifying the priority areas for the changes in clinical practice but also reducing the caesarean rate. Safe reduction of the rate of primary caesarean deliveries will require different approaches for each indication. Individualization of the indication and careful evaluation, following standardized guidelines, practice of evidenced-based obstetrics and audits in the institution, can help us limit Caesarean section rate.

\section{ACKNOWLEDGMENTS}

Authors would like to acknowledge the Medical Records Department of our institution for allowing me to access the in-patient record files.

Funding: No funding sources

Conflict of interest: None declared

Ethical approval: The study was approved by the Institutional Ethics Committee

\section{REFERENCES}

1. Wagner M. Choosing caesarean section. Lancet. 2000;356:1677-80.

2. Petrou S, Henderson J, Glazener C. Economic aspects of cesarean section and alternative modes of delivery. Best Pract Res Clin Obstet Gynaecol. 2001;15:145-63.

3. Belizan JM, Althabe F, Barros FC. Rates and implications of Cesarean Sections in Latin America: ecological study. BMJ. 1999;319:1397-402.

4. Kambo I, Bedi N, Dhillon BS. A critical appraisal of Cesarean section rates at teaching hospitals in India. Int J Gynaecol Obstet 2002;79:151-8.

5. Harper V, Hall M. Trends in caesarean section. Current Obstet Gynaecol. 1991:224-8.

6. Mukherjee SN. Rising cesarean section rate. J Obstet Gynecol India. 2006;56(4):298-300.

7. Stanton C, Ronsmans C. Recommendations for routine reporting on indications for caesarean delivery in developing countries. Birth. 2008;35:20411.

8. Torloni MR, Betran AP, Souza JP, Widmer M, Allen $\mathrm{T}$, Gulmezoglu M, et al. Classifications for caesarean section: a systematic review. PLoS One. 2011;6:e1456.

9. Singh G, Gupta ED. Rising incidence of caesarean section in rural area in Haryana, India: a retrospective analysis. Internet $\mathbf{J}$ Gynecol Obstet. 2013;17(2):1-5.

10. Naidu PNJ. Obset Gynecol India. 1962;12:549.

11. Chakravarty J. Obset Gynecol India. 1971:21.

12. Kumar A, Thakur S. Maternal complications in caesarean section deliveries. J Obstet Gynecol India. 1996;20:36-40.

13. Usha S. A clinical study of caesarean section. 1980.

14. Unnikrishnan B, Rakshith P, Aishwarya A, Nithin K, Rekha T, Prasanna P, et al. Trends and indications for caesarean section in a tertiary care obstetric hospital in coastal South India. AMJ. 2010;3(12):821-5.

15. Geidam AD, Audu BM, Kawuwa BM, Obed TY. Rising trend and indications of caesarean section at the university of Maiduguri Teaching Hospital, Nigeria. Ann Afr Med. 2009;8:127-32. 
16. Subedi S. Rising rate of cesarean section- a year review. J Nobel Med Coll. 2012;1(2):72-6.

17. Haider G, Zehra N, Munir AA, Haider A. Frequency and indication of caesarean section in a tertiary care hospital. Pak J Med Sci. 2009;25(5):791-6.

18. Hafeez M, Yasin A, Badar N, Pasha MI, Akram N, Gulzar B. Prevalence and indication of caesarean section in a teaching hospital. JIMSA. 2014;27(1):15-6.

19. Mutihir JT, Daru PH, Ujah IAO. Elective caesarean sections at the Jos university teaching hospital. Trop J ObstetGynecol. 2005;22(1):39-41.

20. Sobade AA, Archibong EI, Eskander M. Primary caesarean section in nulliparous and grand multiparous Saudi women from Abharegion: indication and outcome. WATAM. 2003;22(3):232

21. Ali L, Tayyab S, Parveen F. Caesarean c-section rate, current trends. J Surg Pak. 2007;12(2):64-6.

22. Dinas K, Mavromatidis G, Dovas D, Giannoulis C, Tantanasis T, Loufopoulos A, et al. Current caesarean section delivery rates and indications in a major public hospital in Northern Greece. Aust N Z J Obstet Gynaecol. 2008;48(2):142-6.

23. Ali L, Tayyab S. Caesarean section rate, curremt trends. J Surg Pak. 2007;1:62-6.

24. Choudhary SM, Ayaz A. Efforts to reduce caesarean section Rate. J Surg Pak. 2003;8(1):25-30.

25. Guise JM, Hashima J, Osterweil P. Evidence-based vaginal birth after caesarean section. Best Pract Res Clin Obstet Gynaecol 2005;19(1):117-30.

26. Spong CY, Lanndon MB. Risk of uterine rupture and adverse perinatal outcome at term after caesarean delivery. Obstet Gynaecol. 2007;110(4):801-7.

27. Kugler E, Shoham-Vardi I. The safety of a trial of Labour after caesarean section in a grand multiparous population. Arch Gynaecol Obstet. 2008;277:339-49.

28. McMahon MJ, Luther ER, Bowes WA Jr, Olshan AF. Comparison of a trial of labor with an elective second cesarean section. $\mathrm{N}$ Engl J Med 1996;335(10):689-95.
29. Gonen R, Tamir A, Degani S, Ohel G. Variables associated with successful vaginal birth after one caesarean section: a proposed vaginal birth after caesarean section score. Am J Perinatol 2004;21:447-53.

30. Subhashini R, Uma N. Changing in caesarean delivery. IAIM. 2015;2(3):96-102.

31. Dabbas M, Al-Sumadi A. Cesarean section rate: much room for reduction. Clin Exp Obstet Gynecol 2007;34:146-8.

32. Murphy D, Sellers S, MacKenzie IZ, Yudkin PL, Johnson A.A case-control study of antenatal and intrapartum risk factors for cerebral palsy in very preterm singleton babies. Lancet. 1995;346:1449-54.

33. Thaker SB, Stroup DF. Continuous electronic heart rate monitoring for fetal assessment during labour. Cochrane Database Syst Rev. 2001;(1):CD000063.

34. Gupta M, Garg V. The rate and indications of caesarean section in a teaching hospital at Jaipur, India. Int J Reprod Contracept Obstet Gynecol. 2017;6:1786-92.

35. 3Mehta A, Apers L. Trends in cesarean section rates in a maternity hospital Mumbai. India J Health Popl Nutr. 2001;19(4):391-7.

36. Dunne C, Dasilva O, Schmidta G, Natale R. J Obstet Gynecol. 2009;31(12):1124-30.

37. Jawa A, Garg S, Tater A, Sharma U. Indications and rates of lower segment caesarean section at tertiary care hospital-an analytical study. Int $\mathbf{J}$ Reprod Contracept Obstet Gynecol. 2016;5:3466-9.

38. Singh A, Reema C. A recent way of evaluating cesarean birth. J Obstet Gynecol India. 2009;59(6):547-51.

Cite this article as: Mathur P, Patel A. Trend of caesarean section at two Government Medical College in Madhya Pradesh, India over one year of time period: a retrospective comparative study. Int J Reprod Contracept Obstet Gynecol 2018;7:2212-7. 